\title{
Internship Program Management Information System with Lean Management
}

\author{
Marco Jr. N. Del Rosario and Ronnel A. Dela Cruz
}

\begin{abstract}
Internship program intends to empower students with real-world knowledge, skills, and desirable attitudes by allowing them to gain hands-on experience. This study focuses on implementing lean management principles in developing a web-based information system that manages the data and processes undertaken by the students in their internship program. The system was developed using the Rapid Application Development (RAD) model which was divided into four main modules. These modules are for monitoring and supervision of the internship program. The system will help the coordinators to manage documents, the supervisor to give grades, the students to create a journal that will monitor progress, and the administrator to manage the system. To determine if the developed system is efficient and functional, trials were conducted utilizing test scenarios, test cases, and comparison table. The developed system was evaluated using a survey questionnaire based on ISO 25010 software quality model as to Product Quality. It obtained an overall mean of 4.32 with a standard deviation value of 0.666 . This validates that the objectives of the study were met and achieved. Moreover, the system was able to reduce the cost and time spent from the previous process, which proves that it successfully integrated lean management principle in its design.
\end{abstract}

Index Terms-Distance learning, internships and co-ops, lean management principle, online education.

\section{INTRODUCTION}

The Internship Program is meant to provide students with an opportunity to complement their formal learning with practical knowledge, skills, desirable attitudes and gain hands-on experience in recognized Host Training Establishment [1]. Hundreds to thousands of students enroll in this course each year since its offering. This course allows the students to acquire more learning and experience, aside from a classroom set-up. There are requirements to be submitted for the program to be taken, and during the training, monitoring of the student's status and progress is closely monitored. This course designates a coordinator that will manage needed documents and will monitor each of the students to be done manually, hence challenging on their part. For instance, the students' recommendation letter is typed and printed out by the coordinator by utilizing the traditional system. These procedures result to a lot of problems like missing and redundant data, communication challenges, interruptions in the grading process, and demands in student monitoring [2].

Manuscript received June 1, 2021; revised August 1, 2021. This work was supported in part by the Laguna State Polytechnic University.

The authors are with the College of Computer Studies in Laguna State Polytechnic University, San Pablo City 4000, Laguna, Philippines (e-mail: macky.delrosario@1spu.edu.ph,ronnel.delacruz@1spu.edu.ph).
These problems are faced by the two main actors, namely, the coordinator and the student. The current practice makes the coordinator to meet the needs all the students manually [3]. Thus, this results to the heavy workloads of the coordinator which includes preparing and managing all the necessary documents required for every student, not limited to, the recommendation letter, waiver, and contract. It is also their duty to monitor the progress of the students, which is challenging to perform because of restriction in distance since the students are away from the university. Furthermore, the huge number of students to be closely monitored is a challenge [3]. Likewise, students experience difficulties in getting necessary documents for the training and problems in monitoring the number of hours they have rendered during the internship. Also, since the current system is performed manually, it is prone to error, less efficient service, and a voluminous usage of paper.

To address such an issue, a perceived solution to the problem poses by the manual system is to develop a web-based information system that will serve as an Internship Program Management Information System. This system would try to reduce these problems and help the related actors in this training procedure from the beginning until the end.

Generally, the objective of the study is to develop a web-based information system for managing the Internship Program in the Laguna State Polytechnic University (lspu.edu.ph). Specifically, this study aims to 1) design and develop an Internship Program Management Information System (IPMIS) that is capable of enhancing the current system. A system that can reduce the workload of the coordinator and help them monitor the progress of the students. A system that can minimize the cost and time expense by implementing lean management concept. In addition, this system can provide other features such as generate letters and journal reports and automatically calculate the time rendered by the students, to assists them to monitor their progress/status. 2) test the developed system as to its functionality and efficiency. 3) evaluate the developed system using an evaluation tool that adapts the ISO 25010 software quality using the product quality composition.

\section{RELATED LITERATURE}

\section{A. Internship}

Internship program in the education process has a significant contribution to improving the quality of competent graduates [4]. It is imperative in higher education to provide students with opportunities to experiential learning [5]. To achieve this, a university requires a student 
to learn outside the classroom. However, this activity undoubtedly necessitates assessment and observation from the university. As a result of such an arrangement, the coordinator faces problems like difficulty in monitoring the internship activities that the students are doing during the training period [6]. In addition, the coordinators were not able to visit most of the company locations to know what the students are doing. This means that monitoring is not wholly being carried out [4]. Common reasons for this dilemma are the restraint of distance, shortage of time, and expensive cost.

Another problem faced by the coordinators is the preparation and management of documents. In a manual system, all related documents such as approval form, evaluation form, progress or monitoring form are being submitted to the coordinator in hard/printed copy. Loss of documents, lack of storage space, and delay of submission are some of the unexpected problems this practice can sometimes cause [2], [7]. Encountering these difficulties while catering hundreds of students at a time can hinder the effective document management of a coordinator.

The monitoring of a student internship program is typically assessed based on the students' internship journal. The students' perception and reflection of his journal system were being evaluated to improve students' work in the internship [4], [5]. Students are required to submit their journals for advising and monitoring [4]. Having a journal provides students an avenue to enhance the learning by associating their knowledge in theory and practice. Having a way of recalling things a student learned during the internship program is very helpful [2], [5].

\section{B. Lean Management Principle}

Lean management adopts several principles from the Toyota production system [8]. Most apparent of these are the zero-waste principle and continuous quality improvement principle. One fundamental element in implementing lean management is by having a systematic approach for improvement for a maximized value of product/service by eliminating waste [8]. This principle aims to develop a long-term systematic plan of achieving little but steady improvement in the processes in order to enhance efficiency and quality. It distinguishes each step in a business process and afterward modifying or eliminating steps that do not create value in an attempt to remove any waste of time, effort, or money [9].

Lean management has several points of interest, some of which are a decrease in expenses, improved clientele interactions, and an increase in quality [10], [11]. In a production system, enforcing a lean concept helps in reducing the production cycle time and overall expenses, particularly in indirect expenses, while maintaining the practice of quality standards [8]. Implementing a pull system in production helps in determining if there is an actual demand in order to utilize the resources better. When production is based on real demand, it is easier to identify the exact amount of resources needed, which will result in reducing time in production and expense on resources [11]. To improve clientele interaction, lean management starts by having the clientele's perspective. How a clientele communicates with staff, how responsive staff can be with their concerns, and how knowledgeable they are with the product are some of the main factors and basis used in removing inefficient practices to improve interaction. Lastly, the increase in quality in lean management denotes reducing errors. It implies that the workforce can avoid wasting time in doing the product again by avoiding committing mistakes, thus optimizing the process [10]. In this manner, actions that bring value to the process will be the focus of the workforce [11].

\section{Methodology AND Project Design}

\section{A. Methodology}

This study is a developmental research because it involves the systematic study of designing, developing, and evaluating the Internship Program Management Information System. In this design, the process of development is analyzed and described, and the final management system is evaluated. Furthermore, the participants in this research varied according to phases. The researchers are the designers and developers of the management systems and the student interns and internship coordinators are the clients and evaluators. In this study, they are referred to as the actors in the design. The IPO model shown in Fig. 1 served as the conceptual model of the study. It served as the guideline in developing the project. This model was divided into three main components, namely Input, Process, and Output component. The input component encompasses all the necessary requirements needed before starting the construction of the system. The requirements are further divided into three subcategories. First is the knowledge requirement, which includes the understanding and familiarization of the current workflow of the Internship Program, its policies, and procedures. This consists of the identification of the roles of the coordinator and students based on the previous practice. It also includes knowledge about the concept of Lean Management to be able to provide an effective solution to the problems encountered by the manual processes and then understanding how to develop a system using web technologies, which also leads to the importance of knowledge about programming software. The Software component entails the software technologies that were used in the development, such as HTML, CSS, PHP, and JQuery. A computer server that was used to host the developed system is the hardware requirement.

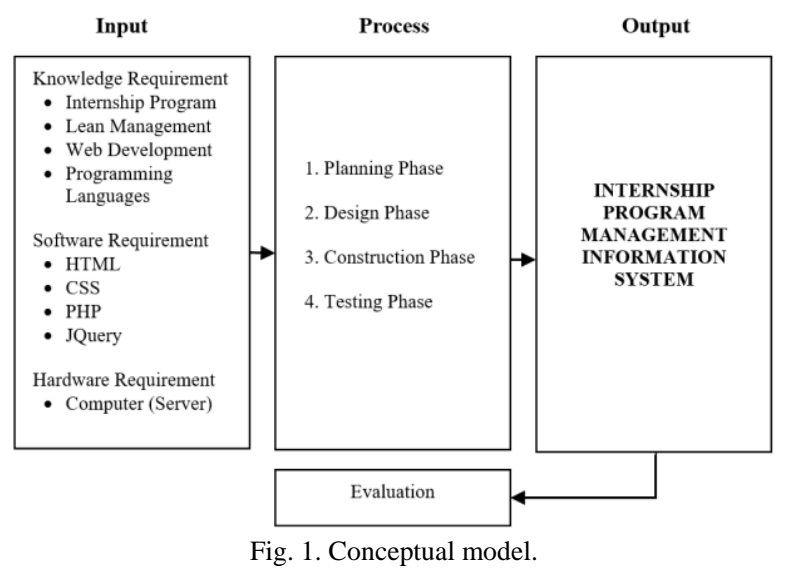


The process component comprises the phases undertaken, and methods performed in the development of IPMIS. Rapid Application Development (RAD) was used in this study. RAD is a methodology for computer system development, which adapted the traditional waterfall model combined with techniques like iterations and prototyping to accelerate the development process [12], [13]. This is a system development method that follows phases such as requirement planning, user design, testing, and implementation [12]. This was selected to produce a working system more quickly than with a traditional method. The planning and design phase is where the proponents decided how the system will work, what processes are involved, who will perform the actions in the system, how to perform such activities, and how the system will look-like. The proponents prepared a Use Case Diagram for identification of the roles of each user and visualization of the system. The system construction phase is where the actual coding is done. This is the phase where the decided design was transformed into a web code.

Different testing was conducted in this study-namely, functionality testing and efficiency testing. In the testing phase, the proponents conducted functionality testing using test scenarios and test cases to determine if all the functionalities offered by the system are working. Another testing was conducted to assess the efficiency of the developed system compared to the manual system. After the process component was performed, the developed IPMIS is the expected output of the system.

The proponents administered an evaluation to identify if the system was conforming to the international standard of software product quality using the ISO 25010. Random sampling was used to select the respondents. The modified Cochran's formula for sample size was used to determine the sample size or the number of respondents. This method was used since there is a small population of fifty-nine (59) [14], [15]. Using this method, the sample size of thirty (30) was derived with a confidence level of $95 \%$ and margin of error of $12.40 \%$. These respondents were selected students who are interns taking Bachelor of Science in Information Technology of the College of Computer Studies. They had completed all the courses required for their program; thus, they are already equipped with the necessary knowledge to use the system and evaluate the product quality of the system in terms of functional suitability, performance efficiency, compatibility, usability, reliability, security, maintainability, and portability. Moreover, the developed system was presented and discussed with the respondents. They were given ample time to utilize the system. Data collection was performed using a survey questionnaire. The instrument used in this research is adapted from ISO 25010 software quality model using the product quality composition that was used in previous scientific journal references dealing with information systems [16], [17]. The questionnaire was answered by the coordinator and the students. The questions were designed to be answered using the Likert Scale. Respondents can answer the items using a scale of 1 (very unsatisfied) to 5 (highly satisfied). This study used descriptive statistics such as mean for statistical data treatment. The Likert scale, mean range, and verbal interpretation are shown in Table I.
TABLE I: SCALE, MEAN RANGE, AND VERBAL INTERPRETATION

\begin{tabular}{lll}
\hline \hline Scale & Mean Range & Verbal Interpretation \\
\hline 1 & $1.00-1.80$ & Very Unsatisfied \\
2 & $1.81-2.60$ & Unsatisfied \\
3 & $2.61-3.40$ & Satisfied \\
4 & $3.41-4.20$ & Very Satisfied \\
5 & $4.21-5.00$ & Highly Satisfied \\
\hline \hline
\end{tabular}

\section{B. Project Design}

Based on the analyzed data on how the internship program at Laguna State Polytechnic University was conducted, the proponents came up with a plan on how the system will work and will be used. The following discussion focuses on the design of what actions a particular user can do in using the system. Use Case Diagram of the plan is illustrated in Fig. 2.

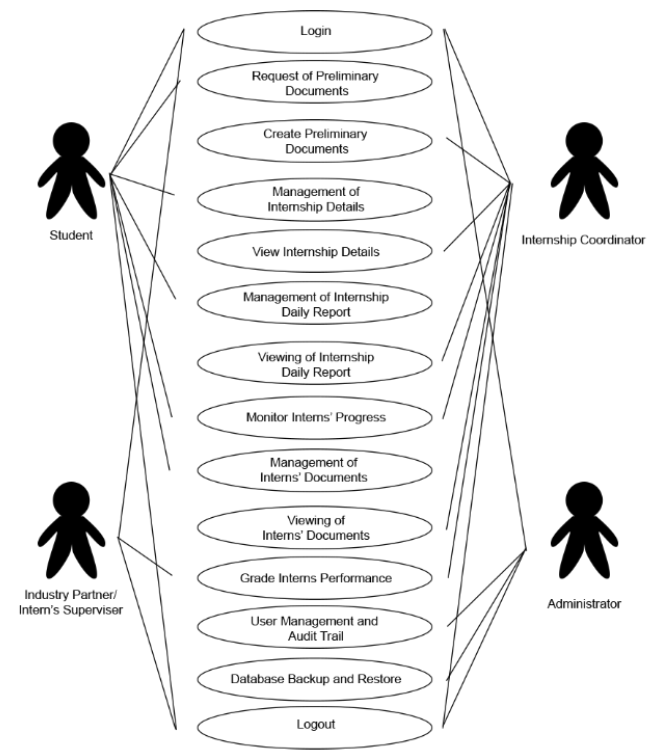

Fig. 2. Use case diagram.

There are four Actors present in the developed system, namely, the Student, the Internship Coordinator, the Intern's Supervisor, and the Administrator of the System. After logging in, a student can perform several actions in the system, which are requesting preliminary documents which will be submitted to the intended company, manage their personal information and details regarding their training, manage daily report or the training journal, monitor their progress based on their time spent in rendering service, and manage submitted preliminary and other necessary documents.

On the other hand, the Internship Coordinator, after logging in, could create the preliminary documents requested by the student by approving the company they chose to render their training. They can also view students' information and internship details, monitor the students' progress, and see their daily report or the training journal as well as view the grade given by the Intern's supervisor with regards to their performance. The Intern's supervisor was also given access to this system to allow them to use a platform where they can assess the performance of the student/intern. Lastly, the Administrator, who will act as the Manager of the system, was given the capability to manage the information of the users of the system. They can add, edit, and archive the information of the users. Furthermore, the system has a 
feature for audit trailing and database backup and restore.

\section{RESULTS AND DISCUSSION}

\section{A. Developed System}

IPMIS is a web-based system that supports the internship program processes of the Laguna State Polytechnic University (Fig. 3a). It includes processes from the beginning up to the end of the program. The system is divided into four modules, corresponding to the users of the system. The student's module allows the students to process pre-training requirements (Recommendation letter. Waiver, and contract), manage the personal account, submit company profile for approval, create the daily journal, and monitor their progress by the automatic computation of the total number of hours rendered in training (Fig. 3b). Moreover, the system allows the intern's supervisor to rate their performance using the evaluation instrument available in the system (Fig. 3c). On the other hand, in the coordinator module, the system grants the coordinator the capability to approve the company the student intends to conduct their training, monitor the number of hours rendered by the students, and view the performance rating given by the evaluator or intern's supervisor (Fig. 3d). Lastly, the system has the administrator module where user management, user logs, and creating database backup can be seen (Fig. 3e).
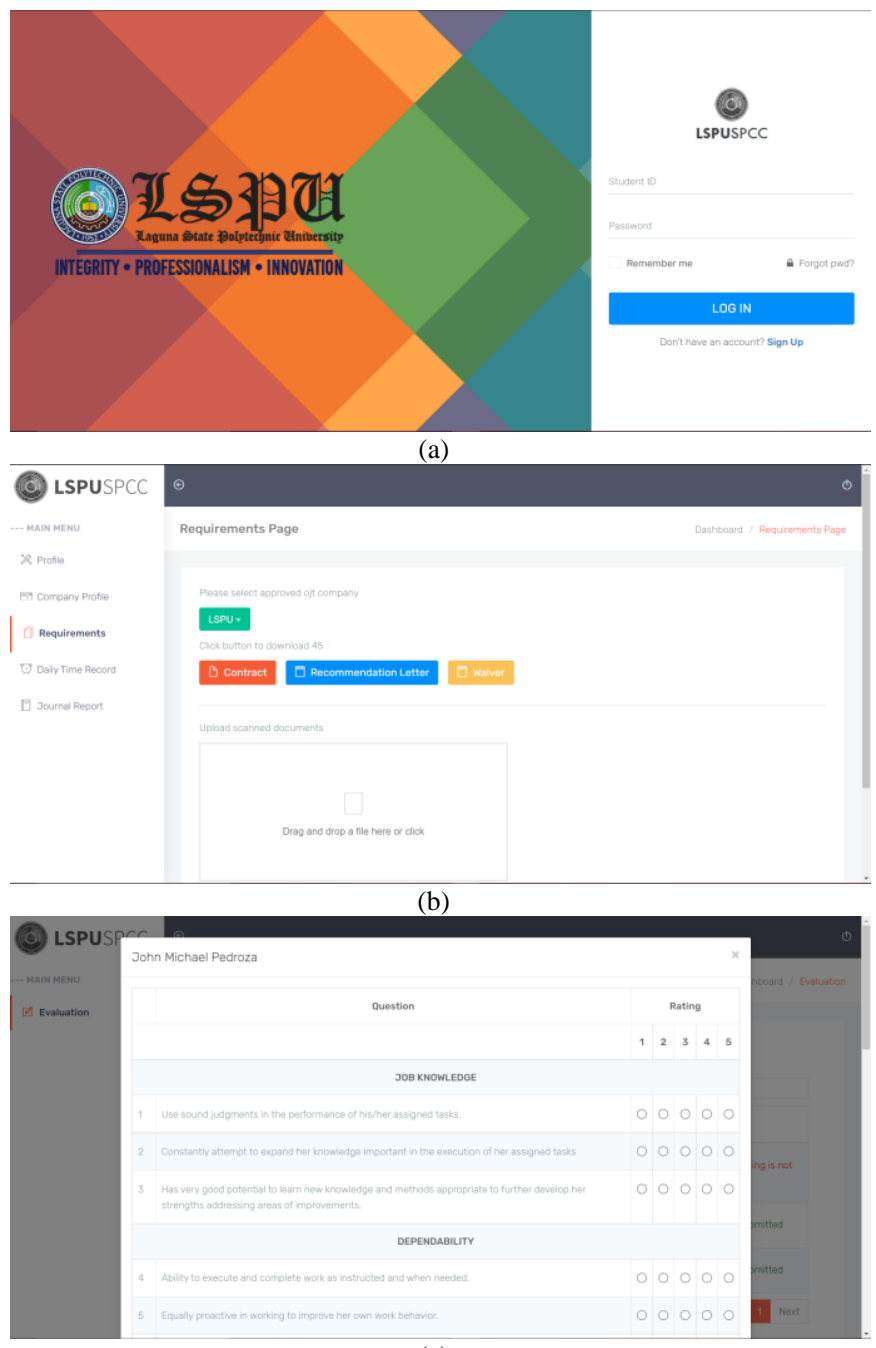

(c)

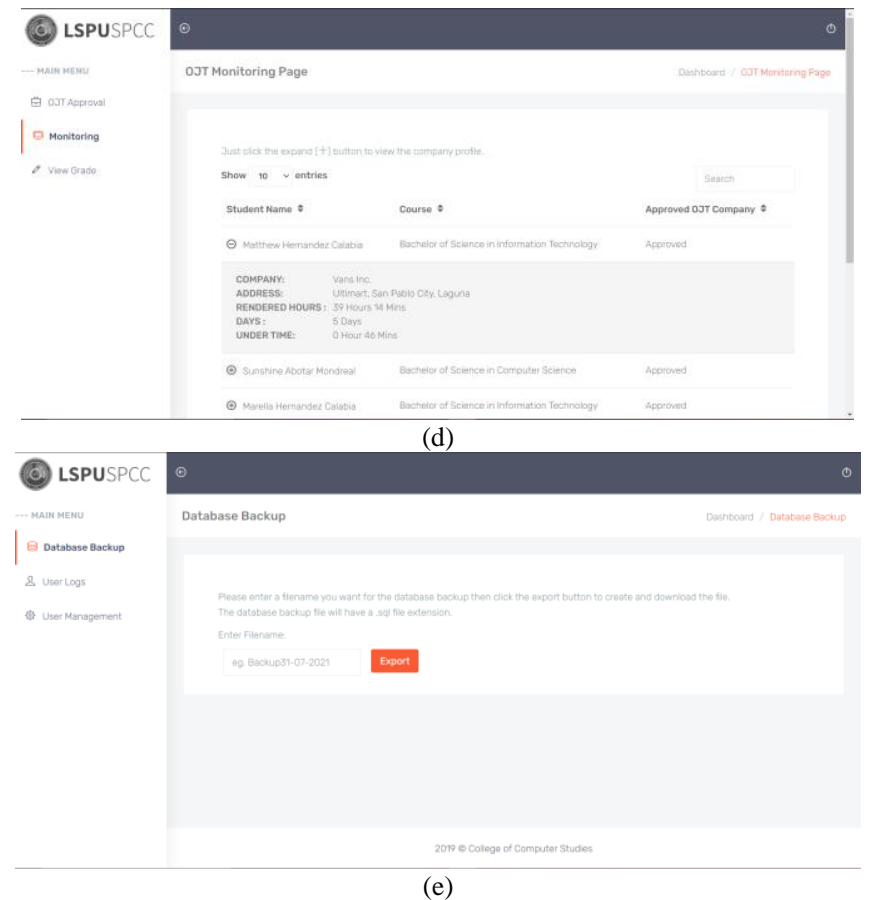

Fig. 3. (a) Home screen (b) student's module (c) intern's supervisor module (d) coordinator's module (e) administrator's module.

\section{B. Testing Result}

Series of testing was conducted to ensure that the developed system has the quality and is functioning as expected. The first testing conducted was to check if all the functions of the system are working and giving correct output. Test scenarios and test cases were prepared and performed in the conduct of this test. A list of test scenarios and the number of test cases performed is shown in Table II. A total of 10 test scenarios were prepared in this testing. Correspondingly, a total of 28 test cases were accomplished to determine the functionality of the system. Each test case was conducted aiming to verify if every function that the system is performing and is conforming to the goals and requirements of the system. The last column in the table title "Remarks" indicates the number of passed and failed test cases.

TABLE II: SUMMARY OF FUNCTIONALITY TEST RESULT

\begin{tabular}{lll}
\hline \hline Functionality / Test Scenarios & $\begin{array}{l}\text { Number of } \\
\text { Test Cases }\end{array}$ & Remarks \\
\hline 1. Login / Logout & 4 & 4 Passed, 0 Failed \\
2. Registration & 3 & 3 Passed, 0 Failed \\
3. Company Profile & 3 & 3 Passed, 0 Failed \\
4. Pre-Training Requirement & 2 & 2 Passed, 0 Failed \\
5. Daily Time Record & 3 & 3 Passed, 0 Failed \\
6. Daily Journal & 2 & 2 Passed, 0 Failed \\
7. Grading Feature & 3 & 3 Passed, 0 Failed \\
8. Monitoring Feature & 2 & 2 Passed, 0 Failed \\
9. Database Backup & 2 & 2 Passed, 0 Failed \\
10. User Logs/Management & 4 & 4 Passed, 0 Failed \\
\hline \hline
\end{tabular}

\section{Legend:}

Passed - indicates that the actual result of the test meets the expected result. Failed - indicates that the actual result of the test was different from the expected result.

The first test scenario conducted was to log in and log out. The test cases included in the Login and Log out test scenario are entering valid username and password, entering invalid username and password, entering one invalid and one valid, 
and logging out to the system. While in the Registration test scenario, entering valid information was tested as well as entering non-valid information and submitting blank fields. The Company Profile test scenario was conducted to check if the student can add, update, and remove the profile of the company they want to render their training. The fourth test scenario focused on the process of downloading the pre-training requirement documents. The download buttons for each requirement were tested if it will download or not the documents based on the approval of the coordinator. The next test scenario that underwent testing was the Daily Time Record test scenario, which determined if the students could fill out the daily time record. Test cases involved are entering complete time in and time out, compute the number of hours rendered and compute the undertime hours. On the other hand, the test cases conducted in the Daily Journal test scenario are entering daily journal reports and updating daily journal reports.

The Grading Feature test scenario determined if the intern's supervisor (evaluator) can submit the performance rating of the student with complete information and incomplete information. Another test case performed in this test scenario was the capability of the system to allow the coordinator to view the submitted rating given by the evaluator. The Monitoring test scenario checks if the coordinator can view the progress of the student based on the total hours rendered and use the search feature to find a specific student. The Database Backup test scenario focused on checking if the system can provide a copy of the database. Test cases were entering a valid filename and entering an invalid filename. Lastly, the User Log and Management test scenario has four test cases conducted. These are listing the user log for audit trail, searching in the user log, adding additional users, and updating user information. All test cases performed showed a positive remark by showing all the expected outputs and postcondition. This means that all test scenarios and their corresponding test cases all passed the testing conducted.

Another testing performed in the conduct of this study was the test measuring the efficiency of the developed system compared to the manual system. This test was conducted to determine if the developed system was integrated with the concept of lean management. As a result, it should be able to remove or lessen the time and cost expense existing in the manual process. It is important to remember that lean management emphasizes on making the processes faster by eliminating waiting time and hold-ups [18]. By eliminating these, there will be more things that could be accomplished and resources that could be saved up, thus improving the efficiency.

Table III shows the results of the comparison between the manual system and the computerized system in terms of the time expense made and the number of visits made. The first process performed in the manual system is that students will request the preliminary requirements from the coordinator, specifically the recommendation letter, waiver, and internship contract. This usually takes about five minutes, since the coordinator will have to create all the preliminary requirements indicating the details of the receiver (company representative) and the intern (student) information. On the other hand, compared to the computerized system, it will only take a minute to generate all three requirements since the information of the interns was already in the system during the registration. The coordinator will only need to approve the request of the intern for them to generate (release) the documents. The manual procedure possibly takes more than one visit from the interns requesting to their coordinator. Since the coordinators have other responsibilities, such as teaching other courses, they are not always available during the process. In the computerized system, the interns do not need to check on them frequently. Instead, they will just check the system for a notification on the approval of the request.

TABLE III: COMPARISON BETWEEN MANUAL AND COMPUTERIZED SYSTEM

\begin{tabular}{|c|c|c|c|c|}
\hline \multirow[t]{2}{*}{ Processes } & \multicolumn{2}{|c|}{$\begin{array}{l}\text { Time expense made per } \\
\text { process * }\end{array}$} & \multicolumn{2}{|c|}{$\begin{array}{l}\text { No. of visit made by the } \\
\text { person involved }\end{array}$} \\
\hline & Manual & Computerized & Manual & Computerized \\
\hline $\begin{array}{l}\text { 1. Request and } \\
\text { Release of } \\
\text { Preliminary } \\
\text { Requirements }\end{array}$ & $6 \mathrm{mins}$ & $1 \mathrm{~min}$ & $>1$ & 1 \\
\hline $\begin{array}{l}\text { 2. Compilation } \\
\text { and } \\
\text { Submission of } \\
\text { Daily Journal }\end{array}$ & 5 mins & 3 mins & $>4$ & 1 \\
\hline $\begin{array}{l}\text { 3. Performance } \\
\text { Evaluation }\end{array}$ & 5 mins & 5 mins & $>2$ & 1 \\
\hline $\begin{array}{l}\text { 4. Compute the } \\
\text { total hours } \\
\text { rendered }\end{array}$ & $50 \mathrm{mins}$ & $1 \mathrm{~min}$ & $>4$ & 1 \\
\hline Total & 66 mins & 10 mins & $>12$ & 4 \\
\hline
\end{tabular}

The second process observed in this test was the creation, compilation, and submission of daily journal reports of the interns. It was estimated that an intern could typically compile and submit the daily report in five minutes. This is naturally comprised of sorting the document report, double-checking, and adding attachments if needed. The computerized system will be faster compared to the manual system by two minutes since the journal was already sorted and submitted. Internship program normally covers the whole semester, about five months, since there are interns that are rendering their training in a distant institution, meetings with the coordinator and submission of daily journal report was done monthly. For that reason, it is expected that an intern has at least four visits to submit their daily journal report. The computerized system helps to lessen the visit of the intern by submitting the daily report through the system.

The performance evaluation process was deemed to have the same time expense made for both the intern and the coordinator because the person involved in giving the mark is the intern's supervisor. However, the manual process lacks efficiency compared to the computerized system in terms of the number of visits. The student will need to visit the coordinator to get the evaluation sheet to be marked by the intern's supervisor. After being given a mark, the intern must return to the coordinator to submit the evaluation. In the computerized system, the intern's supervisor can give the score of the intern to the coordinator through the use of the 
system. There is no need for a physical visit to any party.

The last process observed in this test was the time expense and number of visits needed in computing the total number of hours rendered in training. Calculating the total number of hours rendered helps all parties, intern, coordinator, and intern's supervisor, to know and monitor the progress of the intern. This aspect determines the time remaining if the rendered hours are not yet sufficient, for the intern to undergo training. Since the manual system requires the interns to meet with the coordinator monthly, it can be assumed that there are at least four visits done by the intern, then compute the time rendered for monitoring of progress by the coordinator. It can also be assumed that calculating the hours rendered in a month will take about ten minutes. That is the reason why fifty minutes were presented in Table III. On the other hand, the computerized system will only take a minute to compute the total number of hours rendered by the intern. Also, this shows that in the computerized system, the interns are not required to attend the monthly meeting for the monitoring of progress; however, one visit was indicated for the end of the training.

Table III shows that there is a difference of fifty-six (56) minutes from the sixty-six (66) minutes time expense of the manual system and ten (10) minutes of the computerized system. The manual system expects more than twelve (12) visits from the interns and coordinator. While the computerized system only supposes the intern to visit the coordinator four (4) times that are on the start and end of the training. This depicts that the computerized system is more efficient compared to the manual system. This also means that the system was able to successfully integrate the lean management concept since the cost and time expense were lessened by a large margin.

\section{Evaluation Result}

The performance of the project was evaluated using a questionnaire adapting the ISO 25010 software quality model in terms of the Product Quality composition. All the respondents' ratings were consolidated and computed. Table IV summarizes the evaluation results from the respondents' ratings showing the mean and standard deviation per criterion and the corresponding qualitative interpretation. The table also presents the overall mean by getting the average of all the means of the eight criteria.

TABLE IV: RESULT OF RESPONDENTS' RATINGS

\begin{tabular}{llll}
\multicolumn{2}{c}{ TABLE IV: RESULT OF RESPONDENTS' RATINGS } \\
\hline \hline Criteria & Mean & $\begin{array}{l}\text { Standard } \\
\text { Deviation }\end{array}$ & $\begin{array}{l}\text { Verbal } \\
\text { Interpretation }\end{array}$ \\
\hline Functional Suitability & 4.44 & 0.623 & Highly Satisfied \\
Performance Efficiency & 4.43 & 0.629 & Highly Satisfied \\
Compatibility & 4.12 & 0.732 & Very Satisfied \\
Usability & 4.42 & 0.631 & Highly Satisfied \\
Reliability & 4.27 & 0.674 & Highly Satisfied \\
Security & 4.16 & 0.735 & Very Satisfied \\
Maintainability & 4.29 & 0.643 & Highly Satisfied \\
Portability & 4.39 & 0.657 & Highly Satisfied \\
Overall Mean & 4.32 & 0.666 & Highly Satisfied \\
\hline \hline
\end{tabular}

The respondents' rating regarding the Functional Suitability of the system obtained a mean of 4.44 , which means the respondents are highly satisfied. The functional objective of the project, which is to assist the students, intern supervisor, and coordinator in the conduct of the training, is being met. The data also shows that there is a low variability with a standard deviation of 0.623 .

In terms of Performance Efficiency, a mean 4.43, which is deemed highly satisfactory, was achieved. This means that the system performs efficiently according to its goal. The system was able to process the request on a particular module in a short amount of time (e.g., compute the total number of hours). The data for the Performance Efficiency value also shows a low variability (SD: 0.629).

With regards to the evaluation of the Compatibility criteria, it attains an average score of 4.12, which means that most of the respondents are very satisfied with this criterion. This points out that IPMIS can share the same platform, which is a web browser, with other systems since it is a web-based system. However, the system cannot exchange information with other systems used in the university, thus having the lowest mean of all the criteria. The compatibility criterion got a standard deviation value of 0.732 also indicating a low variability on the data.

The respondents' ratings regarding the Usability criteria obtained a mean of 4.42 , which is interpreted as highly satisfactory. This means that respondents find the system very easy to operate and control. The system's capability to validate responses before submitting contributes to this criterion since it protects them from making errors. A standard deviation value of 0.631 also show low variability in terms of the system's usability.

In terms of Reliability, a mean score of 4.27, which corresponds that the respondents felt highly satisfied with the system. Since IPMIS is a web-based system, a client-server architecture was implemented, which means that once published online, it will be easily accessible whenever required. This also means that in case of hardware or software failure in the user side (client), the data in the server are still safe and recoverable, the user can reestablish the connection to access the data, hence making the system reliable. The standard deviation value of 0.674 also shows how minimal the dispersions are in the data.

A mean of 4.16 denotes that the respondents are very satisfied with the system's security. Since there are multiple kinds of users of the system, it ensures that its features are only accessible to those who are authorized to use it. The system has the capability to share information with other users; however, the other user cannot modify those data. Also, the system has a user log feature for the system to record every user's action and for the administrator to trace and identify the activity of a user. However, the security criterion got the highest standard deviation value of 0.735 among all the criteria.

The respondents' rating regarding the Maintainability criterion got a mean of 4.29 , which means the respondents are highly satisfied. The system was developed in several components bearing in mind the testability of the features and modularity concept in programming. Thus, integration and modification in some areas or aspects in the system are possible and will have no to minimal effect on other components. A standard deviation of 0.643 indicates a low variability on the data.

In terms of Portability, the system attained a mean of 4.39 , 
which is deemed highly satisfactory by the respondents. Since IPMIS was intended to be accessed using a web browser, it can effectively and efficiently adapt to a different web browser. It was build using HTML, CCS, PHP, and JQuery; therefore, updates in different web browsers would not affect the performance of the system. The data also shows that there is a low variability with a standard deviation value of 0.657 .

The functional suitability criterion obtained the highest mean, while the compatibility criterion got the lowest mean. The overall mean computed for all the criteria in the ISO 25010 software quality model in terms of the Product Quality composition is 4.32 , which validates that the system has accomplished its expected purposes according to the objectives, and this further indicates that the respondents are highly satisfied with the quality of the system.

\section{CONCLUSION AND RECOMMENDATIONS}

Prior to the development of IPMIS, the internship program management, and monitoring process has been handled manually by the internship coordinator. In response, this study successfully designed and developed a web-based information system for managing the Internship Program at the Laguna State Polytechnic University. The system was designed with the use of a Use Case Diagram for visualization. It was created through Rapid Application Development and technologies like PHP, JQuery, CSS, and HTML. IPMIS was integrated with the lean management principle, which resulted in significantly lessening wastes like cost and time expense. Modules were created for the students, intern's supervisor, coordinator, and administrator to support the purpose of the system. Students were able to send the company for approval, access an online journal system, and monitor their progress through the calculated total hours rendered. The coordinator was able to approve a company profile and monitor the progress and grade evaluation of the students. Performance grades of the student were also managed using the system. A module to manage user, user logs, and backup the database were developed for the administrator.

Tests and an evaluation were conducted with regards to system functionality, efficiency, and quality. The functionality of the system was tested using 10 test scenarios, with a total of 28 test cases covering all the functions present in the system. After performing the test, the system was able to meet the expectations and was considered functional. In terms of efficiency, the test proves that the computerized system is more efficient compared to the manual system by reducing approximately 56 minutes of processing time and eliminating eight visits of the intern to the coordinator. The system was evaluated using ISO 25010 in terms of product quality composition, which was found highly satisfactory by the respondents. The evaluation revealed that the criteria for Functional Suitability ranked highest. It was followed by performance efficiency, usability, portability, maintainability, reliability, security, then compatibility.

Obviously, the evaluation would have yielded more decisive results if there were more respondents. The study only considered the BS Information Technology interns as the respondents of the evaluation. Hence, the findings may be different from a different program or college. For example, a student enrolled in a different program or under different college might have more documents to process and submit. Also, other programs may not understand the criteria used in evaluating the software quality. Thus, a different test not focusing on the quality of the software, for example design-related factors such as user interface and navigability, should be administered to those students. The study did not investigate the usability and impact of the developed system to the university. Therefore, a follow-up study is recommended.

\section{CONFLICT OF INTEREST}

The authors declare no conflict of interest.

\section{AUTHOR CONTRIBUTIONS}

M.J. N. Del Rosario conducted the research, designed the system, conducted the testing, and wrote the paper; R.A. dela Cruz headed the development of the software program, conducted the evaluation, and wrote the paper; all authors had approved the final version.

\section{ACKNOWLEDGMENT}

The authors are indebted to the College of Computer Studies San Pablo City Campus of Laguna State Polytechnic University and the respondents of the study. The author would like to acknowledge Assoc. Prof Cecilia Diva, for her assistance in language editing, and Mr. Allen Pasia, for his assistance with the statistical work of this research project. Lastly, the authors extend their sincere thanks to $\mathrm{Mr}$. Matthew Calabia for his contribution to this study.

\section{REFERENCES}

[1] Commission on Higher Education, "CHED memorandum order No. 104 series of 2017. Revised guidelines for student internship program in the Philippines (Sipp) for all Programs," 2017.

[2] Y. C. Fei, W. Waheeb, and S. B. Sulaiman, "Student internships: A selective review," Journal of Applied Technology and Innovation, e-ISSN: 2600-7304, vol. 4, no. 2, pp. 1-5, 2020.

[3] A. N. Jaafar, S. Rohafauzi, N. I. Enzai, F. D. H. M. Fauzi, N. N. S. N Dzulkefli and M. T. Amron, "Development of internship monitoring and supervising web-based system," in Proc. 2017 IEEE 15th Student Conference on Research and Development (SCOReD), Putrajaya, 2017, pp. 193-197.

[4] A. Juhana, A. G. Abdullah, M. Somantri, S. Aryadi, D. Zakaria, N Amelia, and W. Arasid, "E-Portfolio web-based for students' internship program activities," IOP Conference Series: Materials Science and Engineering, vol. 306, no. 1, p. 012003, IOP Publishing, 2018.

[5] L. J. ChanLin and W. H. Hung, "Evaluation of an online internship journal system for interns," Procedia-Social and Behavioral Sciences, vol. 191, pp. 1024-7, 2015.

[6] M. Hussain, S. Ahmad, and K. Kamal, "USM internship and career portal," International Journal of Applied Engineering Research, vol 11, no. 20, 2016, pp. 10247-10251, 2016.

[7] S. I. Ismail, R. Abdullah, S. A. C. Kar, N. Fadzal, H. Husni, and H. M Omar, "Online project evaluation and supervision system (oPENs) for final year project proposal development process," in Proc. 2017 IEEE 15th Student Conference on Research and Development (SCOReD), pp. 210-214, 2017

[8] N. A. A. Bakar, T. Z. T. Mat, F. M. Fahmi, and S. T. Urus, "Lean management practices and its effect on Malaysian local government performance," Asia-Pacific Management Accounting Journal (APMAJ), vol. 12, no. 2, pp. 79-104, 2017. 
[9] M. Rouse and E. McLaughlin. What is lean management. SearchCIO. TechTarget. [Online]. Available: https://searchcio.techtarget.com/definition/lean-management

[10] Status Articles. 6 Benefits of Lean Management (And 4 Disadvantages). [Online]. Available: https://status.net/articles/lean-management/

[11] Kanbanize. What is lean management? Definition \& Benefits. [Online]. Available: https://kanbanize.com/lean-management/what-is-lean-management/

[12] R. Delima, H. B. Santosa, and J. Purwadi, "Development of Dutatani website using rapid application development," IJITEE (International Journal of Information Technology and Electrical Engineering), vol. 1, no. 2, pp. 36-44, 2017.

[13] R. F. Tias, M. N. Hamidah, A. Arizal, and F. Setyatama, "Smart school management system of presence monitoring teacher as a realtime with RAD (rapid application development) method at Khadijah High School Surabaya," Journal of Electrical Engineering and Computer Sciences, vol. 6, no. 1, June 2021.

[14] G. D. Israel, Sampling the Evidence of Extension Program Impact, Gainsville, FL: University of Florida Cooperative Extension Service, Institute of Food and Agriculture Sciences, EDIS, 1992.

[15] W. G. Cochran, Sampling Techniques, 2nd Ed., New York: John Wiley and Sons, Inc. 1963.

[16] M. D. Rosario and J. Sareno, "Theses and capstone projects plagiarism checker using kolmogorov complexity algorithm," Walhalla Journal of Science and Technology (WJST), 2019.

[17] M. D. Rosario, "Student paper comparison system using kolmogorov complexity and diff algorithm," Thai Journal of Physics, vol. 36, no. 1, 2019.

[18] Leanopedia. How does lean production improve efficiency? 4 Steps to Getting It Right. [Online]. Available: https://leanopedia.com/how-does-lean-production-improve-efficiency/

Copyright $\odot 2022$ by the authors. This is an open access article distributed under the Creative Commons Attribution License which permits unrestricted use, distribution, and reproduction in any medium, provided the original work is properly cited (CC BY 4.0).

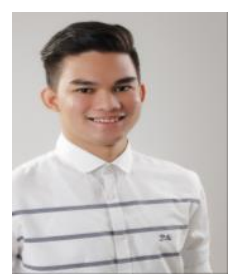

Marco Jr. N. Del Rosario was born in Filipino in November 1994. He received his bachelor's degree in information technology from the Laguna State Polytechnic University and a master of information technology degree from the Technological University of the Philippines.

He is currently a member of the Faculty of the College of Computer Studies at Laguna State Polytechnic University, Philippines. He published papers related to improving local government processes and using string matching algorithms in a computer software to detect plagiarism.

His research interests include web systems development, performance and reliability analysis of computer software, e-government, it education, and elearning.

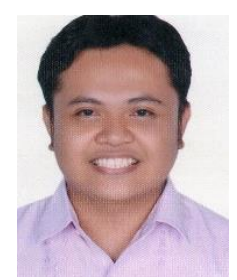

Ronnel A. Dela Cruz was born in San Pablo city, Laguna, Philippines on December 09, 1986. He finished his master's degree in information technology at Polytechnic University of the Philippines - Open University System on December 11, 2015. Currently, he is enrolled in the doctorate in information technology at AMA University, Quezon City, Philippines.

$\mathrm{He}$ is currently working as an instructor in Laguna State Polytechnic University - San Pablo City Campus and designated as the Associate Dean of the College of Computer Studies. Information technology in education is one of his primary interests in terms of research.

Mr. Dela Cruz is a member of various IT organizations in the Philippines like the Philippine Schools, Universities and Colleges Computer Education and Systems Society, Inc., The International Education Circle, Asian Intellect for Academic Organization and Development Inc., Philippine Society of Information Technology Educators Foundation, Inc., and the Philippine Association of Institutions for Research, Inc. 